\title{
CARBON STORAGE RESPONSES OF SUBALPINE FORESTS TO MOUNTAIN PINE BEETLE OUTBREAKS UNDER CURRENT AND ALTERED CLIMATE REGIMES IN WESTERN NORTH AMERICA
}

\author{
DANIEL M. KASHIAN \\ WAYNE STATE UNIVERSITY $\uparrow$ DETROIT
}

\begin{abstract}
$\downarrow$ ABSTRACT
Understanding how climate, disturbances, and carbon storage interact in subalpine forests is critical for assessing the role of this ecosystem in the global carbon budget under altered climate scenarios. Most research to date in western North American forests has focused on wildfire effects on carbon storage and net ecosystem productivity (NEP). The current extensive insect outbreak in this region, however, suggests that insects such as the mountain pine beetle (MPB) are an important driver of carbon dynamics and may determine whether western landscapes are carbon sinks or sources. The overall objective of this study is therefore to understand how MPB outbreaks affect forest carbon storage at stand and landscape scales under multiple climate scenarios. Specific objective include examining how carbon storage changes with stand development following beetle outbreaks, how variability in outbreak extent, frequency, and post-outbreak stand development affect landscape-scale carbon storage, and how beetle outbreaks and climate interact. This research will, for the first time, provide data documenting post-outbreak carbon dynamics under current and altered climate scenarios. These data will provide the basis for developing a carbon-based, ecological rationale for future outbreak management in western forests.
\end{abstract}

\section{$\downarrow \quad$ INTRODUCTION}

Subalpine forests in western North America sequester and store significant amounts of carbon (C) whose storage and release is regulated by disturbances correlated to climate (Kashian et al. 2006). Insect outbreaks are second only to wildfires as the largest source of tree mortality in western North America (Samman and Logan 2000); about $40 \%$ of lodgepole pine forests in the western U.S. are currently susceptible to MPB attack (Hicke and Jenkins in press). Mortality associated with outbreaks clearly affects forest structure, particularly tree regeneration and canopy cover and live and dead biomass, as well as processes including productivity (Romme et al. 1986) and stand recovery (Fleming et al. 2002). These changes may significantly influence forest $\mathrm{C}$ balances in ways very different than fires (Kurz and Apps 1999), but understanding how C storage in western forests responds to MPB outbreaks under current and altered climates represents a substantial knowledge gap.

Climate is a major driver of insect outbreaks in western North America (Carroll et al. 2004, Fastie et al. 1995, Logan and Powell 2001). Projected climate change may influence the extent, severity, or frequency of future outbreaks (Fleming 2000, Hicke et al. in press, Logan et al. 2003), potentially affecting whether a regional forest gains or loses $\mathrm{C}$ to the atmosphere (Kurz and Apps 1999). Currently, a series of mountain pine beetle (MPB) outbreaks 
unprecedented in extent are affecting nearly 10 million ha of forests in the western United States and Canada (USDA Forest Service 2005). Despite their potential implications for $\mathrm{C}$ storage, the impacts of insect outbreaks on forest productivity and $\mathrm{C}$ cycling are poorly quantified and poorly understood. This lack of baseline data represents an important problem because it prevents meaningful predictions of the rate and direction of post-outbreak changes in $\mathrm{C}$ cycling in forests under the current climate. These predictions are critical for assessing future inputs of carbon to the atmosphere via natural disturbances under altered climate scenarios.

The proposed research will provide currently missing data describing the potential for western North American forests to be converted from $\mathrm{C}$ sinks to $\mathrm{C}$ sources following MPB outbreaks. This contribution is significant because it will provide the basis for understanding outbreak influences on forest ecosystem processes and for modeling future $\mathrm{C}$ dynamics in the context of continued environmental stresses on forests, including climate change. The overall objective of this research is to understand how MPB outbreaks affect forest $\mathrm{C}$ storage at landscape scales under multiple climate scenarios. The central hypothesis of this work is that by reducing net primary production and increasing decomposition at stand and landscape sales, MPB outbreaks will cause forests to act as a short-lived $\mathrm{C}$ source to the atmosphere before returning to a $\mathrm{C}$ sink weakened by the outbreak. Furthermore, climate change leading to larger, more frequent, or more severe outbreaks will exacerbate this trend. I am testing this central hypothesis by addressing the following three specific questions:

\section{How does carbon storage vary with forest stand development following a beetle outbreak?}

The working hypothesis for this objective is that an outbreak creates a short-lived $\mathrm{C}$ source to the atmosphere followed by a weaker but long-lived $\mathrm{C}$ sink as stands recover because it reduces stand net primary production and increases decomposition.

2. How do beetle outbreak extent, frequency, and post-outbreak stand development patterns interact to influence C storage at landscape scales?

I am hypothesizing that the landscape will act as a short-lived $\mathrm{C}$ source following an outbreak before returning to a $\mathrm{C}$ sink, but that the $\mathrm{C}$ stored and sequestered on the landscape as a sink will be substantially reduced.
3. What is the potential for climate change over the next 50-100 years to strengthen the feedback between beetle outbreaks and climate?

My working hypothesis is that climate change will reduce $\mathrm{C}$ storage on forested landscapes because it will increase severity, extent, and/or frequency of outbreaks, and that changes in forest structure following outbreaks will affect future outbreak events.

This work will build upon an existing, extensive data set that describes changes in $\mathrm{C}$ cycling following wildfire along replicated, long-term chronosequences (Kashian et al. in preparation). Using this approach, Question \#1 will provide empirical-based modeling of stand development and C storage following MPB outbreaks, and the quantification of the effects of MPB-induced tree mortality on $\mathrm{C}$ storage and loss. Question \#2 will use stand measurements to quantify landscape-level changes in C storage following MPB outbreaks and will provide the basis for understanding the implications of climate-induced changes in MPB outbreaks for C dynamics. Question \#3 will predict the effects of potential climate change scenarios on MPB outbreaks and associated $\mathrm{C}$ storage in subalpine forests over the next 50 to 100 years. The work will be applicable at local and regional scales because it will provide information to managers about the natural variability in insect-related disturbances across landscapes; this information is applicable to most subalpine landscapes in the Rocky Mountains. At national scales, the research will increase our understanding of landscape carbon storage following broad-scale disturbances (in this case insect outbreaks), which is important knowledge that may contribute to the formulation and revision of policies affecting the global carbon cycle and climate change.

\section{$\uparrow \quad$ METHODS}

In the field, four separate chronosequences were identified based on their age when attacked and percent mortality of overstory trees due to beetle kill, each including a control and four time-since-attack classes (undamaged, 1-2 years, 3-5 years, 15-25 years, and 25-35 years) for a total of 72 stands. Because Yellowstone National Park has experienced relatively little beetle mortality, most stands in the first two age classes (12 years and 3-5 years since attack) were located in the Bridger-Teton National Forest, with a few in Grand Teton National Park. A majority of stands in the two oldest age classes were located within Yellowstone National Park. Stands 
were used to quantify all forest carbon pools (aboveand belowground vegetation, snags, coarse woody debris, forest floor, and soil).

Stands were readily accessible by road or trail (i.e., within 1 kilometer of a road or trail). Each stand (cluster) includes three $10 \times 50 \mathrm{~m}$ plots, spaced 20-50 meters apart depending on the size of the polygon, with plots located at equal distances along a baseline. Each plot includes two belt transects along each of its long-axis borders. Belt transects were used to measure standing live and dead trees, stumps, and saplings, with transect width differing for overstory trees and saplings based on density. The center line of each belt transect was also used to select trees and saplings for allometric measurement and to select locations for sampling soil and forest floor. Twenty-five randomly selected saplings in each plot were measured at the base (total $=75$ per cluster). Ten mature trees were randomly selected for further sampling in each plot along the center line of each plot. For each tree, an increment core was extracted at breast height and the sapwood marked on the core, and tree height, height to crown base, and crown depth was measured. Finally, three dominant (oldest) live overstory trees were selected in each plot and an increment core extracted at the base for age determination.

Coarse woody debris was measured using eight 50-foot transects run due east from each plot; CWD was tallied in five size classes, and classified for decay for the largest size class. For sampling forest floor and soil, five forest floor samples approximately $900 \mathrm{~cm}^{2}$ in area were collected along the center line of each plot; all forest floor material was collected to the top of the mineral soil and composited by plot. Composite samples were weighed in the field, and then subsampled. A soil core was extracted to $30 \mathrm{~cm}$ from the top of the mineral soil within the area the forest floor was collected and separated into a $0-15 \mathrm{~cm}$ sample and a $15-30 \mathrm{~cm}$ sample. Nine litter traps were deployed per stand to estimate annual litterfall, deployed 3 per subplot. Litter traps will be collected in July 2009 and 2010.

Soils and forest floor samples and increment cores were transported to the laboratory under refrigeration. For each soil sample, fine roots were separated from soil, classified into live and dead roots, and weighed. A subsample of soil was then taken, rocks and non-root organic matter removed, and weighed, dried, and weighed again to determine bulk density. Live and dead roots were ground in a Wiley mill and analyzed for percent carbon. Soil samples were ground on a roller mill and also analyzed for percent carbon. Forest floor litter subsamples were weighed, dried to constant mass, and weighed again. Excess soil will be sorted from litter samples, and the litter will be ground in a Wiley mill, subsampled again, and analyzed for percent carbon.

\section{Preliminary Results AND PROGRESS}

Six crew members were hired for the summer of 2009, and a total of 61 stands have now been located and sampled in the field. In each stand, litter traps were deployed and plots were set out and flagged for re-location during the next field season. A potential trouble spot with this design is the difficulty in predicting the mortality (outbreak severity) in a stand currently being attacked; thus much of the 2009 field season was spent remeasuring stands in the 1-3 year and 3-5 year classes to account for any changes in mortality class that had occurred, and many of the stands in these classes were different enough to "switch" classes in the sampling matrix. A total of 13 additional plots were sampled during the 2009 field season. All have been completely sampled, including all vegetation, soil, and forest floor samples. The remaining 3 stands in the 64-stand study design will be located on adjacent National Forests in 2010.

Two work-study students were hired for the winter of 2009 and one full-time assistant was hired during summer 2009 to process samples in the lab collected during the 2008 field season, and all samples have been processed. Given an increased number of samples (due to the addition of the shrub biomass component), four work-study students were hired in January 2010 to process samples from the 2009 field season. As of March, all soil, forest floor, ground cover, and litter trap samples have been processed and sent for CHN analysis. All tree increment cores have been mounted and sanded, and are ready for analysis to be completed before September 2010.

The primary goal for the field season of 2010 is to complete plot sampling for all plots. We will re-sample ground cover biomass in all plots to estimate inter-annual variability and to ensure that collection was completed during peak biomass. Like last year, we will also collect material accumulated in litter traps in the 61 plots sampled last year. At present, we plan to hire six crew members to work a five-week field season during July and August to 
accomplish these goals. Preliminary data analysis from summers 2008-09 will be completed for presentation at the Ecological Society of America Annual Meeting in Pittsburgh in early August.

\section{$\downarrow \quad$ Literature Cited}

Abrams PA. 1995. Implications of dynamically variable traits for identifying, classifying and measuring direct and indirect effects in ecological communities. American Naturalist 146:112-134.

Bachman G. 1993. The effect of body condition on the trade-offs between vigilance and foraging in Belding's ground squirrels. Animal Behavior, 46:233-244.

Barber-Meyer SM, Mech LD, White PJ. 2008. Elk calf survival and mortality following wolf reintroduction to Yellowstone National Park. Wildlife Monographs 169.

Brown JS, Kotler BP. 2004. Hazardous duty pay and the foraging cost of predation. Ecology Letters 7:999-1014.

Clark CW, Mangel M. 2000. Dynamic state variable models in ecology. Oxford (UK):Oxford University Press.

Cook JG, Johnson BK, Cook RC, Riggs A, Delcurto T, Bryant LD, Irwin LL. 2004a. Effects of summer-autumn nutrition and parturition date on reproduction and survival of elk. Wildlife Monographs, 155:1-61.

Cook RC, Cook JG, Mech LD. 2004b. Nutritional condition of northern Yellowstone elk. Journal of Mammalogy, 85:714-722.

Creel S, Christianson D, Liley S, Winnie J. 2007. Predation risk affects reproductive physiology and demography of elk. Science, 315:960.

Houston AI, McNamara JM. 1999). Models of adaptive behavior: an approach based on state. Cambridge (UK):Cambridge University Press.
Jimenez MD, Woodruff SP, Cain S, Dewey S 2005. Wolf-elk interactions on winter range and state managed feed grounds in Wyoming. 2005 Progress Report. U.S. Fish and Wildlife Service, Jackson, Wyoming.

Krause J, Loader SP, Kirkman E, Ruxton GD. 1999. Refuge use of fish as a function of body weight changes. Acta Ethologica 2:29-34.

Lima SL. 1988. Initiation and termination of daily feeding in dark-eyed juncos: influences of predation risk and energy reserves. Oikos 53:3-11.

Luttbeg B, Rowe L, Mangel M. 2003. Prey state and experimental design affect relative size of trait- and density-mediated indirect effects. Ecology 84:1140-1150.

McNamara JM, Houston AI. 1987. Starvation and predation as factors limiting population size. Ecology 68:1515-1519.

Pettersson LB, Bronmark C. 1993. Trading off safety against food: state dependent habitat choice and foraging in crucian carp. Oecologia, 95:353-357.

Preisser EL, Bolnick DI, Bernard MF. 2005. Scared to death? The effects of intimidation and consumption in predator-prey interactions. Ecology 86:501-509.

Raithel JD, Kauffman MJ, Pletscher DH. 2007. Impact of spatial and temporal variation in calf survival on the growth of elk populations. Journal of Wildlife Management 71:795-803.

Rudd WJ. 1982. Elk migrations and movements in relation to weather and hunting in the Absaroka Mountains, Wyoming [Thesis]. [Laramie, (WY)]: University of Wyoming.

Schmitz OJ, Krivan V, Ovadia O. 2004. Trophic cascades: the primacy of trait-mediated indirect interactions. Ecology Letters 7:153163.

Smith DW, Drummer TD, Murphy KM, Guernsey DS, Evans SB. 2004. Winter prey selection and estimation of wolf kill rates in Yellowstone National Park, 1995-2004. Journal of Wildlife Management 68:153156. 
Sweitzer RA, Berger J. 1992. Size-related effects of predation on habitat use and behavior of porcupines (Erethizon dorsatum). Ecology 73:867-875.

Vehanen, T. (2003). Adaptive flexibility in the behavior of juvenile Atlantic salmon: shortterm responses to food availability and threat from predation. Journal of Fish Biology, 63, 1034-1045. 